\title{
Foul Play in Sport as a Phenomenon Inconsistent with the Rules, yet Acceptable and Desirable
}

\author{
Jerzy Kosiewicz
}

Josef Pilsudski University of Physical Education in Warsaw, Poland

\begin{abstract}
Author considers assumptions related to foul play in sport as a phenomenon, that affect the body, psyche, or relationships - various social involvements, conditionings, and determinants of those involved with that particular form of athletic activity. This includes fouls committed on and off the field, as well as those not even related to a particular game. Our considerations include fouls of a verbal or acoustic nature; fouls in the form of printed materials; those in the form of visual commentary in films, TV shows, Internet appearances, whether in feature films, dramatized documentaries, documentaries or reports presented in a different publications, festivals, exhibitions, during which co-participants, adversaries or competitors make comments on past or future events during or beyond the competition.
\end{abstract}

Fouls in sport, particularly those committed by athletes during competition, will always be inconsistent with the accepted rules of the game, that is, with the official regulations. Fouls will also always influence - in more or less annoying, depressing, painful or even tragic ways - the fate and the health of athletes.

No logical - conditional, cause and effect - connection exists between a foul and the rules. Neither the need for nor praise of foul play can stem from the regulations. Yet people directly associated with the sport tolerate it because there is a widespread, quiet acquiescence of such play. Foul play is strongly opposed by supporters of the fair play principle, by those who do not regard sports competition as a phenomenon that can be considered independently beyond moral good and evil.

Foul play is seen also as a desirable phenomenon, when inter alia, regardless of the various penalties imposed on players and team, it helps - in the final balance of losses and benefits - to achieve the planned success. Moreover, it is worth adding that, for instance, the so-called "good foul" in basketball enables one to stop the game clock, the so-called pure-play time of the referee. This creates the possibility of obtaining at least one more point (for a possible 3-point shot from a distance) than the team that executes its two one-point penalty shots granted for the offense (that is, "good foul").

Foul play may also enhance the course of the sports spectacle, and encourage spectators to cheer more frequently. This is particularly important when professional athletic contests are treated as a form of business. The dramatization of foul play as a creation of "game" within a game can also be an additional attraction of the competition; foul play might be used as sophisticated and spectacular trickery, that dismays and hurts in its pragmatic-aesthetic construction, both the referee and the opponent. 
Foul play in sports has so many forms and will probably never lose its popular and sometimes spectacular character. Knowing that, everything should be done to protect players from bothersome health, interpersonal, and cultural disablements resulting from foul play.

\section{KEYWORDS}

sport, foul play, causes of foul play, theatralization of foul play, game regulations, misjudgments, acceptance, desire

\section{Game regulations and foul play}

When examining the occurrence of fouls in sport during a game, a race, a cruise, or other types of direct or indirect competition, we can distinguish a variety of forms among such fouls, as in any case of the appearance of aggression. This applies to fouls that affect the body, psyche, or relationships - various social involvements, conditionings, and determinants of those involved with that particular form of athletic activity. This includes fouls committed on and off the field, as well as those not even related to a particular game. Our considerations include fouls of a verbal or acoustic nature; fouls in the form of printed materials; those in the form of visual commentary in films, TV shows, Internet appearances, whether in feature films, dramatized documentaries, documentaries or reports presented in a different publications, festivals, exhibitions, during which co-participants, adversaries or competitors make comments on past or future events during or beyond the competition.

This phenomenon will remain in conflict with other forms of aggression or violence, the presence of which is not only justified by the rules of a particular sport discipline, but are also supported and encouraged as a statutory element that is required, intrinsic, coherent, instrumental and task-oriented (Kosiewicz 2010a, pp. 284-295, Parry 2002, pp. 205-224) for this discipline.

Fouls in sport, particularly those committed by athletes during competition, will always be inconsistent with the accepted rules of the game, that is, with the official regulations. Fouls will also always influence - in more or less annoying, depressing, painful or even tragic ways - the fate and the health of athletes. When taking into account only the rules of the game and the legislative intents explicitly expressed (included) in the regulations, fouls both in sport and in specific disciplines are negative phenomena. Therefore, they are neither necessary, nor coherent, nor recommended. No logical - conditional, cause and effect - connection exists between a foul and the rules. Neither the need for nor praise of foul play can stem from the regulations. To clarify: this means that the statement concerning the pragmatic rules of conduct, similar to the regulative connotations of legal provisions, does not logically implicate [according to David Hume's concept of naturalistic fallacy (Hume 1947, pp. 67-77, and 1963, Jedynak 1974, pp. 157-159)] that foul play might - or ought to - appear in sports. It cannot be implicated from sports legislation that the major, or even minor - whether secondary or related to particular phase of actions - goal or task for the participants in a sport competition (and people who more or less significantly support players) is, or must be, foul play. Further, it cannot be implied from the regulations, that the use of procedures, techniques and means that enable, facilitate, or lead to the foul play are permitted or recommended - even as a pragmatic or moral duty. Foul play - in accordance with the standards expressed in the provisions of particular sports disciplines - is not implicatively and instrumentally tied to the regulations of sports disciplines. The rules may only predict the occurrence of foul play as undesirable phenomenon and determine a form for its penalization.

\section{Causes of foul play}

The absence of any formal or statutory validation of foul play, that is, the lack of inspirational source for the use of foul play in a particular discipline, does not result in the omission of this kind of play. Thus, why do fouls occur?

1. Foul play might arise from non-statutory emotional impulses aimed at the opponent, with the intent to injure him. It might manifest an illegal form of katharsis, a testimony to the 
overwhelming need to purify negative and stressful tensions. It may also represent an increasing dissatisfaction with the unfavorable course of the competition; an exteriority of negative emotions such as rage and anger; negative aggression against the rival who is the alleged or actual perpetrator of an assumed - and therefore not necessarily real -failure, or who can be perceived as the actual cause of the impending disaster. Anyway, this type of behavior has character of potentiality in the sense that, although the rules of a particular discipline may or may not anticipate its appearance, foul play may, but doesn't have to, appear.

2. The provisions of a competition may contain hidden (implicit) suggestions regarding what can be done to achieve the assumed goal (the goal might be more or less important, of a greater or lesser range, related to a lower or higher stage of competition, proximate or further, temporary or final) aside from the accepted and recommended (in conformity with applicable regulations) tactical-technical solutions specific to a certain sports discipline.

3. Rules of the competition might - according to those involved in a particular sport - create a corset that restricts creativity, as well as too harshly and too oppressively hampers the progress, approach, and eventual achievement of the pursued objectives. To act against the rules is to manifest a desire for freedom, for liberation from imposed and sometimes irrational constraints. These actions can contribute to adjustments in the regulations, to the tightening or easing of rules occurring in the regulations; it might lead to the incorporation of changes of a nature too difficult to predict.

4. The foul may either be accidental, or more or less carefully planned. In either case, it surprises all (when it happens randomly or accidentally) or only some participants of the competition, players, coaches, and observers (when it is formerly planned.) Fouls can be skillfully and sensibly - from the standpoint of efficiency and effectiveness - woven into the structure of the game and used as a tactical or strategic option (Simon 2007, pp. 223-226). Warren P. Fraleigh calls this kind of foul an "intentional tactical rules violation" (Fraleigh 2007, pp. 212-213). LiHong (Leo) Hsu defines it after Fraleigh as a "good foul" or a "professional foul" (Li-Hong 2005 , pp. 6-7). Foul play in the indicated cases affects the alternation of the spatial and tactical texture of the game, evoking unexpected emotions, and curiosity that is caused by unanticipated changes in the situation. Leaving out the more or less tragic consequences that result from foul play, such as in health for example, and looking from the structural and formal position, it could be conceived that this phenomenon might have positive and beneficial implications.

5. A foul play may originate from a player's desire to achieve pleasure, pleasure that arises with the foul. This applies to a situation when the player is satisfied with the successfully executed application of a deliberate (not accidental) technical variant of a foul that results in the interruption of the game's running time and is harmful to the opponent (and his team) who was fouled. The foul is also disadvantageous in terms of the fouled player's assumptions regarding the process of the competition. Paradoxically, this type of foul play may have taking into account the motivation of the perpetrator - an autotelic, and not instrumental, nature. The foul becomes for the perpetrator the goal itself; it does not serve as a means for achieving pragmatic or utilitarian objectives. Therefore, it is the pursuit and fulfillment of the expectation of good fun. Foul play, as considered by a good fan, is an example of certain type of pure fun. Though this type of good fun happens at someone else's expense, fouling regardless of autotelic motives - is also the negation of the rules that are in force in a given discipline. The consequences are threefold:

a) an experience of pleasure and quite particular egoistic sense of fulfillment of the player's own selfish needs,

b)an exposure of the victim of the foul to the psychological, physical, and relational discomfort; the same danger of exposure relates to the team that is associated with the 
completion of victim's sport-related objectives,

c) an exposure of the perpetrator of the foul and his team to more or less severe penalization; to random loss of opportunities on the way to planned victory, loss that is not associated with the tactical assumptions of the game.

In the five aforementioned reasons for fouls, when considering them in terms of transparency of intention, we deal with two kinds of foul play.

The first type is characterized by a deliberate fraud, a planned hoax; a foul, in which the real intentions are not available to the referee. Foul play in this case is a manifestation of a sort of "game" within a game that is based on the intentional misleading of a referee. In the second type of foul, we are dealing with open, transparent, and conscious foul play. The nature of this second type of foul is obvious with regards to the benefits that the player will gain when the foul will be noticed and, according to the rules of the game, punished. The intention of the player and his team in the second case is for "a game" within the game to be noticed, and identified as such. Applied by referee, punishment might bring both the player and his team essential advantage in the final balance of benefit and loss. Such a possibility occurs, for example, in some situations in basketball.

Regardless of the situation, in both cases we are dealing with the manipulation of referee behavior. The objective of the manipulation is to force the referee to behave and act in a manner that the player committing the foul assumes and expects. It's worth mentioning that a foul in which the intention of player is disguised, opens - in opposition to the foul with transparent and clear intention, a so-called good foul - for the referee two possibilities: he can either punish the actual perpetrator of the offense or, he can punish the fouling player's victim. In the first case, the referee does not proceed in accordance with the intention of the manipulator, does not surrender to the fouling player's manipulation, does not follow his suggestion and identify the manipulative character of "a game" within the game. In the second case, the referee complies with the fouling player's suggestions, he acts as the manipulator had assumed.

Therefore, it can be assumed that the evident way of foul play - from the perspective of those who like to consider the foul play in light of the principles of fair play - is a more negative form of behavior than the foul play skillfully disguises or masks. The case of a transparent foul might be called "open, obvious or insolent" foul play (Goffman 1981, p. 104). However, in both cases, not only are the rules of the game are violated (which seems to always be a negative quality from the point of view of the supporters of fair play), but even worse, the decisions of the referee are manipulated.

6. Foul play may also occur as non-intentional mistake, which, among others aspects, could be testimony to:

a) bad training or preparation for competition,

b) the manifestation of fatigue and loss of the necessary physical and mental agility of a player,

c) mental and physical incapacity caused by, for example, the occurring and developing ill condition,

d) an improper, in the particular situation, selection of technical and tactical means,

e) improperly prepared sports infrastructure: for example, an incorrectly prepared football field, athletic track, cycling races tour, horse or car tour,

f) poorly prepared, poorly matched, or badly designed sports equipment,

g) bad weather conditions: rain, snow and, related to this condition, slippery surface on which the games are played,

h) major mental stress caused by the influence of an aggressive and demanding attitude of rivals during the game, the negative impact of mass media, fans, club owner, trainer; or excessive expectations of other team members. 
Is foul play able to bring benefits: a) to the practice of competitive sports, and b) to a sports event by increasing its attractiveness? Undoubtedly yes. Among others, these following reasons might assure a positive answer:

1. The observations stated above in point number three indicate that foul play may (not necessarily directly) result in, inspire, or highlight the need to introduce some (or even significant), positive changes, especially valuable for the competitive sport (Reddiford 2002, 231-232). Foul play may in fact contribute to: the modification of the competition's regulations or the provisions of particular discipline; to the exacerbation or mitigation of ensuing fouls; and to a significant or less noticeable (but still significant in term of potential damage) reduction of the possibility of more or less distressing trauma.

2. In response to the second question posed above, foul play might in many ways significantly contribute to the change of spatio-temporal, spontaneous or planned structure, blueprint or scenario of an event and its cognitive and emotional reception. Foul play may, for instance, contribute to the temporary removal of a competitor or the removal of a greater number of athletes from ongoing competition. This may also result in the temporary or permanent removal from athletic circles, or even in a shorter or longer removal from society, to a penitentiary system. Foul play not only changes the formal structure of a game, and a game's so-called dramatics, but also - regardless of the legal and moral overtones, that is, withdrawing the multiple axiological and pragmatic contexts as well as the consequences of foul play brings more attention to the course of events (for example, on the field). It also increases the general interest in the fate of the penalized individuals and teams - their careers, and any transfers or changes in the standings of the individual or team.

Why, despite threats of oft-onerous penalties, despite an awareness of harm to health, the individual and social harm of using the foul play, are athletes tempted to consciously risk disgrace and moral condemnation? Why do they decide to become subject to the penalties according to the provisions of the competition and, moreover, subject to the administrative, civil and criminal legal procedures?

a) They pursue the willful victory or a tie. In the first case, for example in football, football players must "intercept the ball from the rivals, conduct an action, in which they will not allow the opponents to knock them down on the field (in fair or unfair approach) and find themselves in a situation in which they might score a goal." And it has to be at least one goal more than the opponents have scored (Janus 2010, p. 34). On the other hand for football players to finish a competition in a tie, they must at least prevent the opponents to score one goal. In both situations, the player must avoid his opponent's unfair, nonregulatory actions, and often by playing strongly against the rivals, a player can get a game closer to a more or less distant aim. Often a player consciously exceeds the game regulations. Foul play may be the key to success, especially if it has an impact on further performance in the competition, or plays a decisive factor in choosing the winner in the championship or in the tournament (Janus 2010, pp. 34-35, 46).

b) They risk because they think that the potential benefits (financial, political, religious, or cultural; ensuing from the current optimum publicity and emerging, growing, and strengthening fame or even immorality) coming from the foul clearly outweigh the possible - but not inevitable - punishment or negative health effects. Usually foul play is made implicitly acceptable by players, secretly endorsed by the whole environment - in the backstage, changing room, field, coaches room, social circumstances - and ethos of sports games, an ethos practiced within their profession. In this respect, the final football match of the 2010 World Cup in South Africa can serve as one of many examples.

c) This type of behavior enjoys quiet approval - despite official proclamations otherwise amongst athletes, coaches, the authorities, teams owners, and the fans. 
d) Beyond doubt, foul play significantly increases a sporting event's attractiveness. This includes:

- heightening the level of the aleatory nature of a sports event by adding unexpected components of performance, or unpredictable (for competitors and observers) situations that occur in both fixed and schematically arranged elements of the event, as well as those which are random,

- enriching the dramatic component of a performance as a licentia poetica of its own kind, by saturating it with here-and-now authentic emotion and effort - that is, with content that is beyond the sport's normal events. Foul play of both kinds - planned and spontaneous - can lead to real personal (and team) tragedy. The hardship might have, inter alia, overtones related to ambition (due to unfulfilled plans, disappointment over broken hopes for applause and fame, or dreams of winning the championship), related to finance (the elimination of resources for further training and maintenance), related to health, or related to damaged national, ideological or political relations.

In theatrical plays, events such wars, fights, mutilations, or the aforementioned individual and interpersonal tragedies are not real. They happen as a part of written and scripted sequence of events as seen on stage; they are designed by the playwright, producer, and director. Although previously planned, they have power to elicit sublime aesthetic and artistic experiences, especially in the case of good performances. Viewers of the show experience deep emotions regarding the success or failure of persons involved in the drama on stage.

Dramatic situations that occur during a sports spectacle, such as a permanent injury or even a death caused in foul play, happen for real: they are not an isolated metaphysical aesthetic composition suspended in a world of artistic abstraction, separated from the real life by a 'fourth wall' or a 'magic curtain'. They cause deep, varied and authentic experiences. They often result in permanent mental, physical and relational changes (e.g., family) in athletes, as well as direct and strong emotional excitement among the observers and fans. A positive perception of the whole event (a structural standalone entity) is influenced by one's presence or even better, participation in a most surprising performance, full of dramatic tension, fouls, and unforgettable changes of action. The greater the mass media attention and public opinion the event garners, the longer it will be remembered.

e) The people responsible for the score, the course and the effectiveness of professional sports competition treat the provisions of particular disciplines both as formalized guides which define the general rules and characteristics, and as general indicators of a competition's limits. The provisions constitute an initial framework, a basis for a road map that contains all the detailed data, that is, the performance's score, in which the primary and pragmatic goal is to win, to succeed (in whatever way this concept is understood). The main and the most important purpose of competition - both in pragmatic and axiological meaning - is not a strict adherence to the rules of the competition, but the optimal use of their content in order to achieve success. The purpose of modern professional sport is not so-called fair play (not to be confused with the principle of pure play), that is, a strict adherence to the rules of the discipline. The purpose of modern professional sport is to use the rules to achieve another, fully utilitarian purpose. Therefore, people who co-create the plan of the game weigh the benefits of, on the one hand, adherence to the rules, and on the other hand, disobedience in order to achieve both short- and long-term goals (even for the price of severe penalties).

Therefore, the variety of fouls can be listed. If the foul is planned in advance and appears to be feasible in predictable situations during the game, we are dealing with so-called tactical fouls. The opposite parties accept them, even if such fouls result in painful consequences. These fouls are in fact included in the profit and loss balance of the game. They are a part of the unwritten agreement, a sort of protocol commonly known in particular circles. There they abide, regardless of the possible effects of the actions of judges, commentators or general public opinion. Analogous is the silent acceptance of the use of various types of doping that occurs in many social and sporting circles, accepted among 
those who remember that, for many decades, drugs accounted for a significant stimulator in the work of eminent artists.

f) One of the reasons for the increased occurrence of foul play is the widespread commercialization of sport - a so called fetish of contemporary times, the importance of which continuously grows. It rightfully intensifies popular interest in sport, especially sports spectacles. This, as well as the increasing expectations of demanding employers who pay huge salaries and bonuses and the expectations of wealthy sponsors hungry for success and ruthlessly enumerating failures - will certainly stimulate the development of foul play and other forms of aggression.

\section{The theatralization of the foul play - or the "play" element in the sport game}

The use of foul play is treated by the players, their coaches, employers and supporters of the team as a constant and essential component of the techniques and tactics of competitive sport.

Foul play is a manifestation of a peculiar game, in another words - manipulation that is aimed to mislead a particular referee. The foul leads to the punishment or even elimination of a competitor, and ultimately weakens the opponent's team; finally it results in the defeat of rivals, who like their fans are embittered by a bad verdict. Van N. Quanquebecke and S. R. Giessner (2010, p. 3) state that "many fouls committed in football (called soccer in some countries) are ambiguous, and there is no objective way of determining who is the 'true' real perpetrator or who 'true' victim".

This foul play as a "game" appears during a normal game, one consistent with the rules. We then deal with a "game" within a game. The offender "plays" the role of the victim. Therefore, we are witnessing a game of quasi-theatrical characteristics. The player who performs a foul skillfully simulates, imitates, and applies acting tricks while playing his role of the victim. The "game" within a game contains secret, carefully hidden and skillfully disguised intentions. In fact, the foul is a psychoand socio-technical procedure aiming to affect - in line with the expectations of the person committing the foul - the referee's decision. The referee does not seem to be conscious of the real causes of the situation and the possible consequences of his wrong conduct. Thus, foul play is a deliberate manipulation, a deception (Fraleigh 2007, pp. 211-212, Li-Hong 2005, pp. 6-7, Reddiford 2002, pp. 225-239, Leaman 2001, pp. 91-99) misleading the arbitrator; it is unfair conduct that hurts rivals - both individuals, as well as a whole team. The referee is objectified and treated instrumentally as a passive tool used to achieve a goal extraneous to him, contrary to his intentions, which was created by one of the rivals.

From the standpoint of a competitor who performs the foul, the considered "game" is a highly risky task that puts him - when his real intentions are discovered - in danger of incurring the deserved punishment, often stiffer than other penalties, as the foul is judged to be intentional fraud.

The competitor undertakes this quite exciting and thrilling procedure either because he likes such extreme challenges, or because it has been assigned to him by the coach as a necessary, but not statutory, technical and tactical operation. His good performance results in - even when the intentions are reprehensible $-\mathrm{a}$ feeling of satisfaction and approval, or even admiration, among members of his team, a coach, and fans. The feeling of disapproval, on the other hand, arises within the injured opponent and people associated with him.

The foul play "game" - which occurs during a football match, for example - requires extraordinary skill. It is performed by top athletes, whose conduct and action usually gains popular moral and professional trust, particularly in a referee and spectators. However, the "game" takes place beyond moral good and evil. It aims to achieve adopted pragmatic advantages: to punish the victim, not the actual offender. The rules are treated as a convention that can be uniquely interpreted and applied as an aid in order to attain a benefit. 
Thus some kind of dramatization, a dramatic act, is happening, when one party pretends to be someone other than he actually is in reality. The foundation for such a play creates thoroughly and reliably learned behaviors, adjusted to existing situations. The basis for the application of the behavior is relevant practical knowledge (phronesis, Gallagher 1992, pp. 151, 152-154, 166, Gallagher 1993, pp. 298-305, Dreyfus 2004, pp. 267-271) and the intuition that indicates at what point and how to play the victim, and, at the same time, in extremely skillful ways blaming the actual victim for the result of a situation.

Reference to the theater is not accidental. Although the incidents or situations that happen are certainly not manifestations of any form of theatrical drama, they do comprise highly aleatoric elements of performance, i.e. sports spectacles (Kosiewicz 2010b, pp. 267-276). They can be defined as an episode or scene, the existence of which was not previously known. Even when it was assumed that a foul is going to occur, it was not generally known where, in what part of a sports arena, and at what point of a sports spectacle.

Such an episode can be compared to an event, a spontaneously played situation that had previously been designed. One person provokes an incident involving, supposedly by accident, selected persons such as rivals and the referee, who is tracking the course of a "game" from the distance during the game. All the people involved in the situation - the opponent and the referee have their roles assigned without their own approval. They are involved in staging regardless of their volitional and emotional attitude to this pre-planned dramatization.

The main operator in the situation, the perpetrator of the event, is a director and at the same time he plays a major, well-planned, and prepared role.

The referee's role can be compared to that of a character from puppet theater - the puppet whose behavior is controlled by a director, the most important participant of the event. In a given play, the role of referee is the worst possible one, since he will be ridiculed if his decision complies with the intention of the director. His is a tragicomic figure, arousing sympathy, as do some characters in the plays of Jean-Baptiste Molière:

a) comic, because he does not realize in time that he has been led astray,

b) tragic, as in fact he is put to shame, loses his authority, and exposes himself to ridicule, mockery, and laughter.

In turn, a player who is involuntarily hurt plays a tragic role, since he is found guilty, even though he is the real victim of the incident.

The culprit, on the other hand, blows his own trumpet, like a hardboiled crime fiction character. Not only that he escaped justice, but that his fraud (his fraudulently used of quasi-imitative acting skills) was generously rewarded. He played the role of victim so suggestively that the referee trusted him.

\section{Sources of referees' misjudgments}

Why can even the most eminent referees, experts of recognized authority with long-standing international practice, be misled?

The cause of their mistakes are primarily rooted in the regulations of particular sports disciplines. The rules require that the perpetrators of the foul will be immediately identified and possibly punished. Therefore, there is no time for in-depth analysis of the event. The time deficit does not allow for consultation with other referees or with any objective observers of the event. No recording devices register the foul play - to play back the video recording would facilitate analysis of the situation.

For example, the referee (main referee) in football makes his decisions based only on his subjective assessment of a given event. It is based literally on one-sided observation, on what he saw 
from one place. While dealing with ad hoc situations, a referee is not allowed to take into account different perspectives of the situation that are available through relevant technology. The event's data are accessible to him from only one perspective, one place.

During boxing matches, at least four judges are present - one referee and three scoring judges. Yet even they make mistakes because they are not able to see everything. Players (not just football players) take this under consideration and with their skillful "game" dupe judges - deliberately injuring their opponents.

Niels van Quanquebecke and Steffen R. Giessner (2010, p. 3) noticed that in the case of popular team sports, such as rugby or American football video, recording devices are used. Re-played in slow motion, the recordings take into account a variety of shots and angles of view. The use of these video recordings ought to serve in resolving ambiguous situations. Meanwhile, the Federation Internationale de Football Association (FIFA) presents in this case a different - definitely conservative - position. The federation opposes the application of new technological solutions by referees (FIFA 2007, Warshaw 2006). FIFA believes - in spite of the examples set by rugby and American football - that such instruments only create the technological illusion of objectivity, and might become in fact the cause of other types of errors and distortions during the game.

It is worth mentioning that football referees often rely on data, which they use as quasi-tips when making decisions in complex, ambiguous situations involving contact on the field (Mascerenhas, O'Hare and Plessner 2006). This refers to implicit suggestions contained in psychological research regarding the various causes and conditions of a foul. Among the factors that may affect the decisions of referees in selected situations, the following can be distinguished: the knowledge that the "colour of the players uniform" (for instance: black) induces aggressive action towards rivals (Frank and Gilovich 1988, Tiryaki 2005). Also, an important influence on the referee's decisions is the context of "preceding foul judgments" (Plessner and Betsch 2001). In their verdicts on an ambiguous situation, referees more or less consciously also take into account opinions about the team and "a team's reputation" (Nevill, Balmer, and Williams 2002). The impact that a player's height has on behavior, such as foul play on the field, was also analyzed. Therefore, the possible application of studies in the field of cognitive psychology is considered, showing an automatic association of tall height with the need to dominate (Quanquebecke and Giessner 2010, p. 4). Taller height gives a sense of strength, power, and physical advantage over rivals (Barsalou 1999, 2008, Glenberg 1997, Niedental, Barsalou, Winkielman, Kraut-Gruber, and Rick 2005, Lakoff and Johnson 1980).

N. van Quanquebecke and S. R. Giessner (2010, p. 14), referring, inter alia, to the aforementioned authors: during seven-year-long studies focused on football matches in the German Bundesliga, the UEFA Champions League, and the FIFA World Cup, it was assumed that taller players foul more often than shorter players, who are more often the victims of fouls. But it was shown that fouls were more often directed at taller players, although it was shorter players that fell down more often, suggesting that it was they who were injured by rivals.

Nota bene: the additional, aforementioned data concerning the determinants of aggressive behavior and foul play are double-edged, because this knowledge is broadly available, not only for referees but also for players and others associated with professional competition, inter alia, those involved in contact team sports. They can use it skillfully, trying to deceive referees during plays involving fouls.

The codification and application of these fouls (with their associated prohibitions and commandments, as well as rules of punishment) must urgently and comprehensively be described, characterized, and constantly updated, because - as an integral part of professional sports - they will always accompany the conduct of competition in a particular discipline of sport as a possible or actual course of action. Formal rules of certain sports should also include - for the information of all concerned - demonstrable, undisclosed, and non-statutory guidelines of the rules used during the competition. It should be available not only for those involved in the particular discipline of sport - the 
fans, journalists, and the general public - but also for children and adolescents, and especially parents, in order to acquaint them with the characteristics of risks in professional sports.

In conclusion, in light of the discussed considerations, foul play is used in sport, although it is not a form of the game that complies with certain disciplines. Yet people directly associated with the sport tolerate it because there is a widespread, quiet acquiescence of such play. Foul play is strongly opposed by supporters of the fair play principle, by those who do not regard sports competition as a phenomenon that can be considered independently beyond moral good and evil (Kosiewicz 2010, pp. 21-29).

Foul play is seen also as a desirable phenomenon, when inter alia, regardless of the various penalties imposed on players and team, it helps - in the final balance of losses and benefits - to achieve the planned success. Moreover, it is worth adding that, for instance, the so-called "good foul" in basketball enables one to stop the game clock, the so-called pure-play time of the referee (Li-Hong 2005 , p. 6, Simon 2007, pp. 223-224). This creates the possibility of obtaining at least one more point (for a possible 3-point shot from a distance) than the team that executes its two one-point penalty shots granted for the offense (that is, "good foul").

Foul play may also enhance the course of the sports spectacle, and encourage spectators to cheer more frequently. This is particularly important when professional athletic contests are treated as a form of business. The dramatization of foul play as a creation of "game" within a game can also be an additional attraction of the competition; foul play might be used as sophisticated and spectacular trickery, that dismays and hurts in its pragmatic-aesthetic construction, both the referee and the opponent.

Foul play in sports has so many forms and will probably never lose its popular and sometimes spectacular character. Knowing that, everything should be done to protect players from bothersome health, interpersonal, and cultural disablements resulting from foul play.

\section{REFERENCES}

Barsalou, L.W. (1999). Perceptual symbol system. The Behavioral and Brain Sciences, 22, 577-609.

Barsalou, L.W. (2008). Grounded cognition. Annual Review of Psychology, 59, 617-645.

FIFA (2007). Platini rules out video replays. Press releases from the 122nd Annual General Meeting of the International Football Association Board. Retrieved September 27, 2007 from http://www.fifa.com/worldfootball/news/newsid=606659.html.

Fraleigh, W. (2007). Intentional Rules Violations - One More Time. In W.J. Morgan (Ed.), Ethics in Sport (pp. 209-218). Champaign, IL: Human Kinetics.

Frank, M.G. and Gilovich, T. (1988). The dark side of self- and social perception: Black uniforms and aggression in professional sports. Journal of Personality and Social Psychology, 37, 74-85.

Gallagher, S. (1992). Hermeneutical Possibilities. In Hermeneutics and Education (pp. 123-168). Albany: State University of New York Press.

Goffman, E. (1981). Czlowiek $w$ teatrze życia codziennego /The Presentation of Self in Everyday Life/. Warszawa: PWN.

Gallagher, S. (1993). The Place of Phronesis in Postmodern Hermeneutics. Philosophy Today, 37, $298-305$.

Dreyfus, H.L. (2004). What Could Be More Intelligible Than Everyday Intelligibility? Reinterpreting Division I of Being and Time In the Light of Division II. Bulletin of Science, Technology \& Society, 24, 3, $265-274$.

Hume, D. (1947). Badania dotyczace rozumu ludzkiego /An Enquiry concerning human understanding/. Kraków: PWN.

Hume, D. (1963). Traktat o naturze ludzkiej /A treatise of human nature/. Warszawa: PWN.

Hume, D. (1974). Związek konieczny /The necessary connection/. In S. Jedynak, Hume (pp. 157-159). Warszawa: PW "Wiedza Powszechna".

Feyerabend, P. (1975). Against the Method. London: New Left Book.

Jones, M.V., Paull, G.C. and Erskine, J. (2002). The impact of a team's aggressive reputation on the decisions of association football referees. Journal of Sport Sciences, 20, 991-100. 
Janus, T. (2010). Czy gra faul jest drogą do sukcesu w piłce nożnej? Analiza gry uczestników Mistrzostw Świata 2010 /Is foul play the way to success in football? Analysis of the play of participants of the 2010 World Cup/. Sport Wyczynowy, 3, 34-46.

Kosiewicz, J. (2010a). Aggression in Sport. In Sport and Philosophy: From Ethics to Sport (pp. 284-295). Warsaw: BK Wydawnictwo i Księgarnie.

Kosiewicz, J. (2010b). The Sporting Spectacle from the Point of View of Aleatorism. In Sport and Philosophy: From Ethics to Sport (pp. 277-283). Warsaw: BK Wydawnictwo i Księgarnie.

Kosiewicz, J. (2010). Sport beyond Moral Good and Evil. Physical Culture and Sport. Study and Research, XLIX, 21-29. DOI: 10.2478/v10141-010-0012-2.

Lakoff, G. and Johnson, M. (1980). Metaphors we live by. Chicago, London: The University of Chicago Press.

Leaman, O. (2001). Cheating and Fair Play in Sport. In W.J. Morgan, K.V. Meier, A.J. Schneider (Eds), Ethics in Sport (pp. 91-99). Champaign, IL: Human Kinetics.

Li-Hong (Leo) Hsu (2005). Revisiting Fair Play: Cheating, the 'Good Foul' and Sport Rules. Academic Supplement of Fair Play! The Official Publication of the European Fair Play Movement, 4, 6-7.

Nevill, A.M., Belmer, N.J. \& Williams, M. (2002). The influence of crowd noise and experience upon refereeing decision in football. Psychology of Sport and Exercise, 3, 261-72.

Niedental, P.M., Barsalou, L.W., Wilkielman, P., Kraut-Gruber, S. and Rick, F. Embodiment in attitudes, social perception, and emotion. Personality and Social Psychology Review, 9, 181-211.

Parry, J. (2002). Violence and aggression in contemporary sport. In M.J. Mcnamee and S.J. Parry (Eds.), Ethics and Sport (pp. 205-224). London and New York: Spon Press.

Reddiford, G. (2002). Cheating and self-deception in sport. In M.J. McNamee and J. Parry (Eds), Ethics and Sport (pp. 225-239). London and New York: Spon Press.

Quanquebecke van, N. \& Giessner, S.R. (2010). How Embodied Cognition Affects Judgments: High-Attribution Bias in Football Foul Calls. Journal of Sport \& Exercise Psychology, 32, 3-32.

Simon, R.L. (2007). The Ethics of Strategic Fouling: A Reply to Fraleigh. In W.J. Morgan (Ed.), Ethics in Sport (pp. 219-227). Champaign, IL: Human Kinetics.

Szacki, J. (1981). Słowo wstępne. In E. Goffman (Ed), Człowiek w teatrze życia codziennego /The Presentation of Self in Everyday Life/ (pp. 5-27). Warszawa: PWN.

Tiryaki, M.S. (2005). Assessing whether black uniforms affect the decisions of Turkish soccer referees: Is the finding of Frank and Gilovich's study valid for Turkish culture. Perceptual and Motor Skills, 100, 51-57.

Warshaw, A. (2006, November 28). Blatter vows to block video evidence in the game. The Independent.

\section{AUTHOR'S ADDRESS: $\quad$ Jerzy Kosiewicz}

Department of Philosophy, Chair of the Social Sciences

Josef Pilsudski University of Physical Education in Warsaw

34 Marymoncka str., 00-968 Warsaw, Poland

Email: jerzy.kosiewicz@awf.edu.pl 